\title{
A Study on the Protection Relay Test and Analysis Method of AC Electric Railway Substation
}

\author{
Dae-Seok Kang ${ }^{1}$, Woo-Sik Won ${ }^{1}$, Byung-Lib Ahn ${ }^{1}$ and Byeong-Gon Lee ${ }^{2}$ \\ 1. EntechWorld, Inc., 196 Gasan Digital 1-ro, Geumcheon-gu, Seoul 08502, Korea \\ 2. Korea Railroad Corporation, 240 Jungangno, Dong-gu, Daejeon 34618, Korea
}

\begin{abstract}
Since opening of the Korean high-speed railway in 2004, the rate of electrification has been increasing rapidly, and safety of the supply of AC railways has become very important. And the digital protection relays in railway feeding system need more attention with the expansion of unmanned SSs (substations) and digital SSs. For accident prevention, it is necessary to develop accurate modeling and simulation technology for railway feeding devices of electric railway. And it is also important to continuously improve test methods and develop excellent relay algorithms and apply them to the protection system to prepare for unexpected accidents. In this study, after reduced modeling the AC railway power supply system using PSCAD/EMTDC (Power Systems Computer Aided Design/Electromagnetic Transient DC Analysis), the results were compared and verified with the numerical calculation using the symmetric coordinate method. It also presents a method of using the verified results for simulation and education for various railway accidents. This study result will be used for the construction of new lines as well as existing lines in the future railway business.
\end{abstract}

Key words: Electric railway, digital protection relay, modeling, PSCAD/EMTDC.

\section{Introduction}

With the opening of the high-speed railway in 2004 in Korea, electric railway technology for safety has also rapidly developed. However, more fundamental countermeasures are needed for large and small accidents that may occur in large-scale personnel transportation [1]. AC electric railway SSs (substations) are installed at intervals of about $50 \mathrm{~km}$, and SP (Section Post) and SSP (Sub-Section Post) are installed between each SS. The SP and SSP installed between each SS are for division and extension of the electric feeding section. These electric rail power supply devices are monitored in real time by a protection relay for safety. The protection relay used in the AC electric railway power system is mostly dependent on foreign products.

Digital protection relay operation algorithms used for power system protection are classified into various types

Corresponding author: Woo-Sik Won, Technical Research Center in Entechworld Inc., research fields: protection relay, fault locator and power quality management. according to application targets such as transmission lines, transformers, buses and generators. Recently, the protection relay has been developing rapidly, but the relay algorithm currently applied is not perfect yet. In particular, since the electric train is a moving load, it is necessary to prepare for unexpected accidents, and to continuously improve test methods and develop excellent relay algorithms and apply them to the protection system. In order to prevent malfunction of the protection relay and fault locator installed for the safety of the railway power supply system, modeling and simulation reflecting the actual field system are required. In addition, it is necessary to develop various solutions to increase users' accident analysis abilities.

In this paper, we investigated the operation and test method of the electric railway power system protection relay. And we have developed the new protection relay for the power supply system evaluation solution based on PSCAD/EMTDC (Power Systems Computer Aided Design/Electromagnetic Transient DC analysis). The developed protection relay evaluation system can be used for various accident simulation and education. 


\section{Electric Railway Digital Protection Relay}

\subsection{AC Railway Protection Relay}

There are BT (Booster Transformer) method and AT (Auto Transformer) method for electric railway power supply method. In the BT method, power is supplied through the catenary line and the sub-feed line, and in the AT method, power is supplied through the feeder line. The two methods are compared as below.

Fig. 1 is the BT method and Fig. 2 is the AT method. The distance between BT SSs is about $30 \mathrm{~km}$ and the distance between AT SSs is $40 \sim 100 \mathrm{~km}$. The AT method is Korean AC Railway's standard and AT SSs are installed at intervals of about $50 \mathrm{~km}$. The distance between SPs and SSPs installed between SSs is about $10 \mathrm{~km}$.

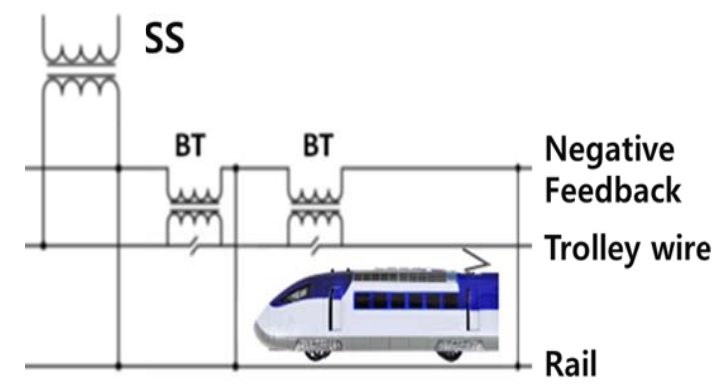

Fig. 1 BT electrical railway power system.

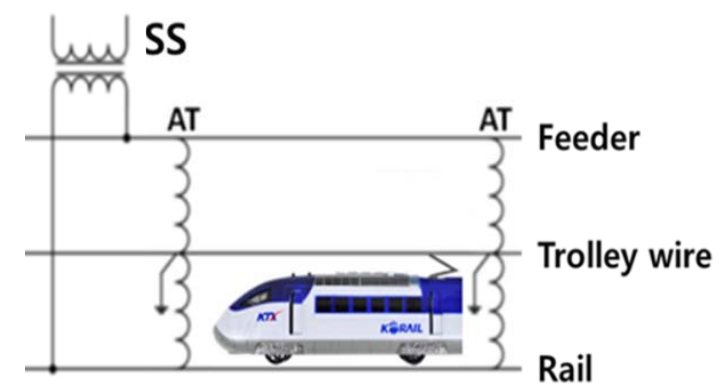

Fig. 2 AT electrical railway power system.

In addition, there are various devices for the safety of electric railways, and the digital protection relay called IED (Intelligent Electronic Device) is a very important device for the safety of electric railway power supply. IED of a recent trend of multifunction is an intelligent computational relay, which samples an input at a predetermined period and converts it to a digital value, and compares and determines whether fault or not by internal algorithm.

Table 1 summarizes the names and installation locations of $\mathrm{AC}$ railway protection relay system. The main AC protection relays used in SSs are differential current relays, overcurrent relays, overvoltage relays, undervoltage relays and distance relays [2].

Table 1 AC railway protection relay.

\begin{tabular}{lll}
\hline ANSI device & Numbers & Remark \\
\hline Overcurrent & $\# 50 / 51(\mathrm{OCR})$ & Feeding section \\
Undercurrent & $\# 37(\mathrm{UCR})$ & SP/SSP \\
Overvoltage & $\# 59(\mathrm{OVR})$ & Receiving section \\
Undervoltage & $\# 27(\mathrm{UVR})$ & Receiving/Feeding \\
Distance & $\# 21$ & Feeding section \\
Differential current & $\# 87$ & Transformer section \\
Fault locator & $\# 99(\mathrm{FL})$ & Feeding section \\
\hline
\end{tabular}

Various accidents occurring in electric railway SS, SP and SSP are summarized in Table 2.

Table 2 SS protection relay failure.

\begin{tabular}{|c|c|c|}
\hline & Fault type & Symptoms \\
\hline $\begin{array}{l}\text { Receiving } \\
\text { section }\end{array}$ & $\begin{array}{l}\text { Short circuit } \\
\text { Ground fault }\end{array}$ & Overcurrent \\
\hline Transformer & $\begin{array}{l}\text { Internal problem } \\
\text { Overvoltage }\end{array}$ & Short circuit \\
\hline $\begin{array}{l}\text { Feeding } \\
\text { section }\end{array}$ & $\begin{array}{l}\text { Short circuit } \\
\text { Ground fault } \\
\text { Undervoltage }\end{array}$ & $\begin{array}{l}\text { Overcurrent } \\
\text { Overvoltage } \\
\text { Unable normal operation }\end{array}$ \\
\hline
\end{tabular}

In the electric railway substation, a problem of burnout of transformers and peripheral devices may occur due to overcurrent accidents due to short circuits and ground faults. In addition, there are some problems of capacity reduction and power supply failure due to insulation breakdown and winding short due to overvoltage in the transformer. The short circuit, ground fault, and undervoltage accidents are frequent failures in the case of the power supply section $[3,4]$. 


\subsection{AC Protection Relay Operation}

The differential current relay $\# 87$ and the distance relay \#21 operate in the event of a ground fault or short circuit accident in the power supply system of the train to block the fault current and contribute to finding the cause of the failure. The following briefly describes the differential current relay and the distance relay. Fig. 3 explains the operating characteristics of the ratio differential relay.

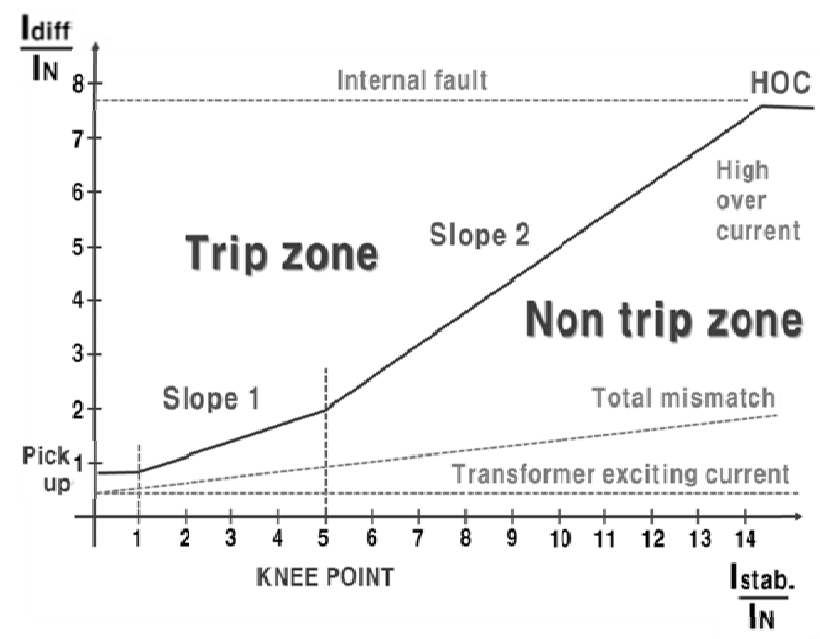

Fig. 3 Test of differential current protection relay.

In Korea's AC power railway SS, Scott and AT transformers are used. The differential current relay \#87 is intended to protect the Scott transformer. In the case of an internal fault of the transformer, the transformer protection relay should be cut off on the primary side, the transformer should be inoperative to the external fault of the transformer or to the normal train operation.

The differential current relay detects the difference between the primary and secondary currents of the transformer in the suppression coil and the operation coil in the relay for internal protection of the transformer to determine whether the relay is in operation. Table 3 describes the correction ratio and suppression current correction conditions of the differential current relay.
Table 3 Differential current protection relay setting.

\begin{tabular}{lll}
\hline Setting range & $\begin{array}{l}\text { Differential } \\
\text { current (\%) }\end{array}$ & $\begin{array}{l}\text { Restrain } \\
\text { current }(\mathrm{pu})\end{array}$ \\
\hline Pick-up current & $15 \%$ & 1.0 \\
Slope 1 & $35 \% \sim 40 \%$ & 5.0 \\
Slope 2 & $70 \%$ & $\geq 10.0$ \\
HOC & $70 \%$ of short circuit & $\geq 10.0$ \\
\hline
\end{tabular}

Fig. 4 describes the operating characteristics of the distance protection relay (\#21). Distance protection relay calculates impedance value from voltage and current input through CT (current transducer) and PT (potential transducer), and determines error and outputs TRIP signal. That is, it is operated by determining the direction and electrical distance from the relay installation location to the point of a short circuit or ground fault [5].

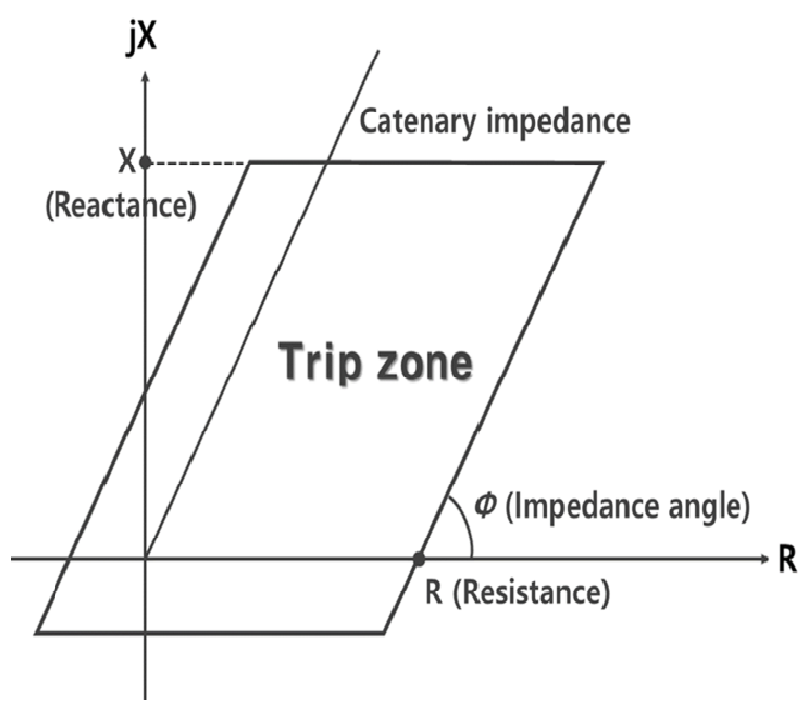

Fig. 4 Test of distance protection relay.

Table 4 describes the distance and time settings for each protection zone of the distance protection relay. In order to prevent malfunction of over- and under-reach in distance relay operation, a correction margin of about $20 \%$ is reflected. 
Table 4 Differential current protection relay setting.

\begin{tabular}{llll}
\hline & \multicolumn{2}{l}{ Distance relay setting } & Purpose \\
\hline Zone 1 & Distance & $85 \% \sim 90 \%$ & Prevent error \\
& Time & $0.05 \mathrm{~s}$ & \\
& Distance & $120 \% \sim 125 \%$ & Expand protection \\
Zone 2 & Time & $0.2 \mathrm{~s}$ & \\
& & & \\
\hline
\end{tabular}

Zone 1 is meant for protection of the primary line and it is typically set to cover $80 \% \sim 95 \%$ of the line length. Zone 1 provides fastest protection because there is no intentional time delay associated with it. Operating time of Zone 1 can be of the order of 1 cycle. Zone 1 does not cover the entire length of the primary line because it is difficult to distinguish the exact fault location. Usually Zone 2 is set to $120 \% \sim 125 \%$ of primary line impedance Zone 1 . This provides sufficient margin to account for non-zero fault impedance and other errors in relaying. Also one should note that Zone 2 also provides back up protection to a part of the adjacent line.

\section{Protection Relay Test and Modeling}

\subsection{AC Railway Protection Relay Test}

The digital protection relay test is divided into static and dynamic characteristics. In the static characteristic test, a simple characteristic of the protection relay is usually evaluated, whereas in the dynamic characteristic test, it is used to check the occurrence of system accidents or malfunctions. Fig. 5 describes the Hardware-In-the-Loop (HIL) test procedure for static or dynamic characteristics. The static test of protection relay is relatively simple but the dynamic test used for very complex accident analysis has a variety of inputs, so the test method is also quite difficult.

In electric railway power systems, most accidents involve large fault currents. So it is very important to simulate the fault current by each fault mode and compare it with the actual value.

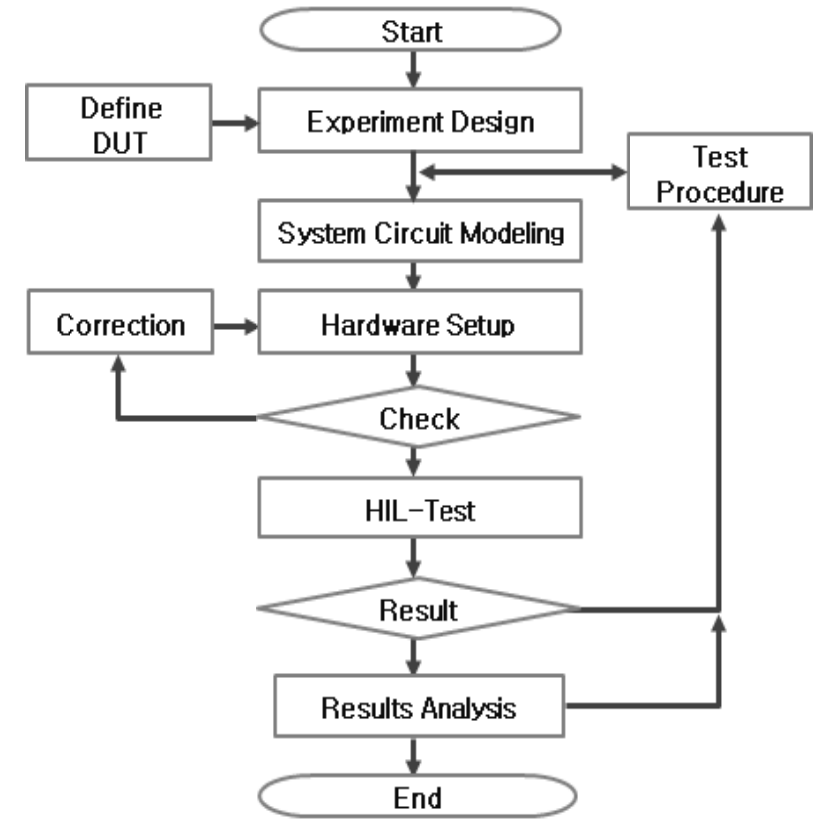

Fig. 5 Protection relay HIL-test procedure.

Fig. 6 introduces several methods for testing the static and dynamic characteristics of the protection relay. The simulation result of RSCAD or PSCAD or the data stored in the protection relay at the accident site are input to the protection relay through an amplifier to determine whether there is a failure. The power system simulation output data or the accident storage data is played back in the form of COMTRADE file and used for accident analysis [6]. In the test of this study, there were two signal channels applied to the protection relay. One is an external analog amplifier and the other is Omicron-CMC356 (protection relay test set).

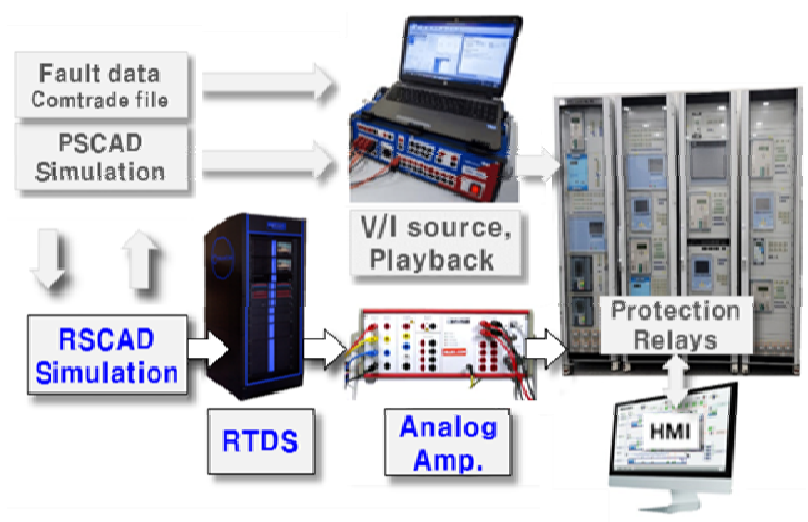

Fig. 6 Protection relay test system. 


\subsection{Electric Railway Power System Modeling}

The electrical power system can be simply modeled and simulated as a circuit configuration of RLC, $\mathrm{V}$-source and I-source based on a 4-port network in order to test electrical faults of the system. Assuming $\mathrm{V} 1$ and $\mathrm{I} 1$ of the input terminal and V2, I2 of the output terminal, it can be expressed as shown in Fig. 7. In the 6-terminal network model, the relationship between voltage and current is expressed as the following Eq. (1), and is used for modeling the actual $\mathrm{AC}$ electric rail power supply system.

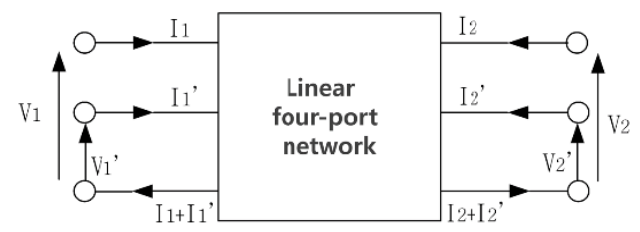

Fig. 7 Linear four-port network.

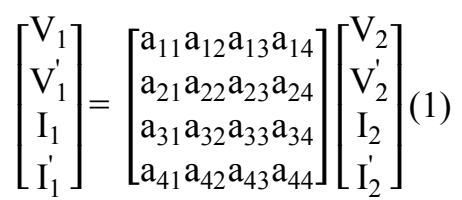

Power is supplied to the load through power sources, transmission lines and transformers. At this time, a voltage drop occurs due to the specific impedance of each device. The impedance at that time is $\% \mathrm{Z}$, which is important in modeling. $\% \mathrm{Z}$ is the ratio of the line voltage drop and the rated voltage as a percentage. Conversion of $\% \mathrm{Z}$ and ohm values is expressed by Eq. (2) when the line voltage is $\mathrm{V}$ and the reference capacity is $\mathrm{Q}$.

$$
\% Z=\frac{Q \cdot Z}{V^{2}} \times 100 \%
$$

The following Fig. 8 shows reduced modeling circuit and simulation circuit of the power supply system of the AC railroad. The electric railway SS receives $154 \mathrm{kV}$ from the KEPCO (Korea Electric Power Corp.) and transforms it into $55 \mathrm{kV}$ in a Scott transformer.

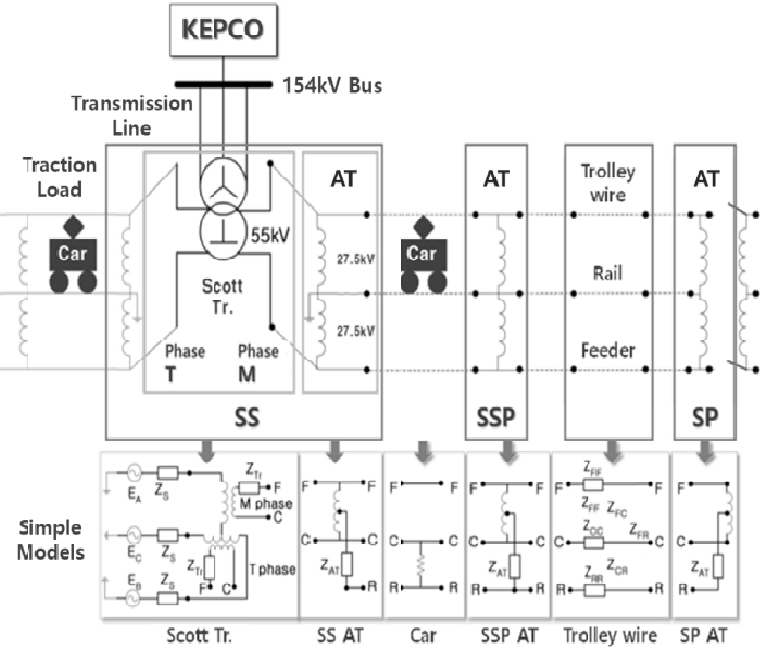

(a) Modeling of electric railway substation

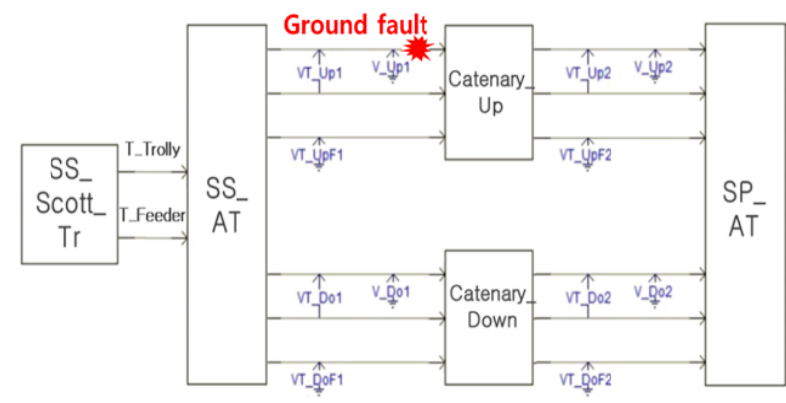

(b) Simulation circuit using PSCAD/EMTDC

Fig. 8 Modeling circuit for AC railway system.

The Scott transformer receives KEPCO's $154 \mathrm{kV}$ 3 -phase power and outputs two $55 \mathrm{kV}$. The $55 \mathrm{kV}$ M-phase and T-phase have only 90 degree phase difference as single-phase outputs.

The AT receives the $55 \mathrm{kV}$ output of the Scott transformer, transforms it into $27.5 \mathrm{kV}$, and supplies it to the feeding line. The autotransformer is connected between the catenary line and the feeder line, and the rail is connected to its center. In other words, the AT supplies $27.5 \mathrm{kV}$ to the catenary-rail and feeder-rail respectively.

In power system modeling, the calculated value and the simulation value were compared by assuming a specific accident in the train feeding system. The numerical calculation using the symmetric coordinate method and the simulation results using PSCAD/EMTDC are compared and used for accurate analysis. 
Table 5 shows the impedance values for the calculation of $154 \mathrm{kV}$ single line-to-ground fault current. The numerically calculated single line-to-ground fault current $\left(I_{g}\right)$ is shown in Eq. (3).

Table $5154 \mathrm{kV}$ single line-to-ground fault impedance.

\begin{tabular}{lll}
\hline $\mathrm{Z}=R+j X \Omega$ & $\mathrm{R}$ & $\mathrm{X}$ \\
\hline Zero sequence component & 1.0296 & 5.2232 \\
Positive sequence component & 0.5853 & 3.8554 \\
Negative sequence component & 0.5853 & 3.8554 \\
Combined component & 2.202 & 12.934 \\
\hline
\end{tabular}

$$
\mathrm{I}_{\mathrm{G}}=\frac{3 \mathrm{E}}{\mathrm{Z}_{0}+\mathrm{Z}_{1}+\mathrm{Z}_{2}}=\frac{3}{13.12} \times \frac{154 \mathrm{kV}}{\sqrt{3}}=20.33 \mathrm{kA}
$$

\subsection{Protection Relay Evaluation System Development}

RTDS (Real Time Digital Simulator) based real-time simulators, which have recently attracted attention as power system simulators, have economic and technical difficulties. So, in this study, we developed a relatively simple PSCAD based IED (Intelligent Electronic Device ; protection relay) simulator as a pre-test tool prior to RTDS based simulation as a new solution, and in the future it can be also used for field education. Fig. 9 is an HIL-test hardware configuration of the IED simulator for electric railways developed based on PSCAD in this study $[7,8]$.

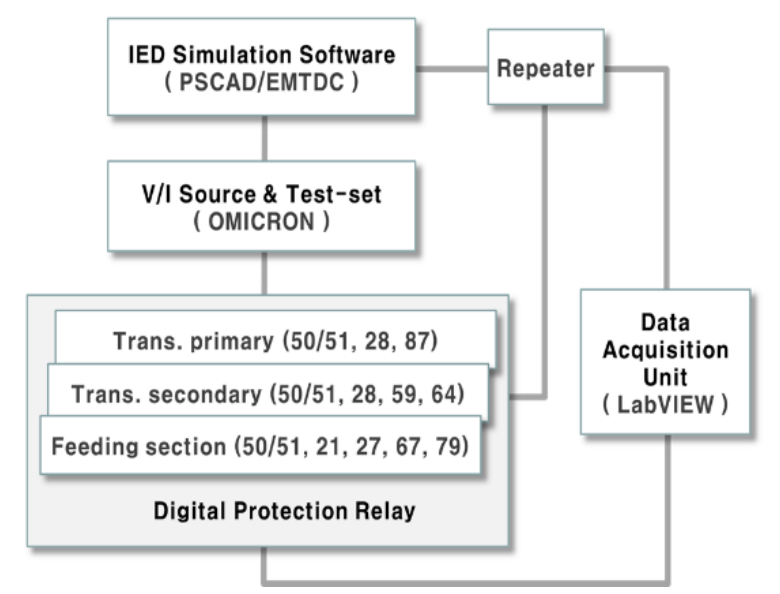

Fig. 9 HIL-test configuration of IED simulator.
The graphic plots in Fig. 10 are the protective relay (\#87, \#21) simulation results obtained from the HIL-test program developed in this study.

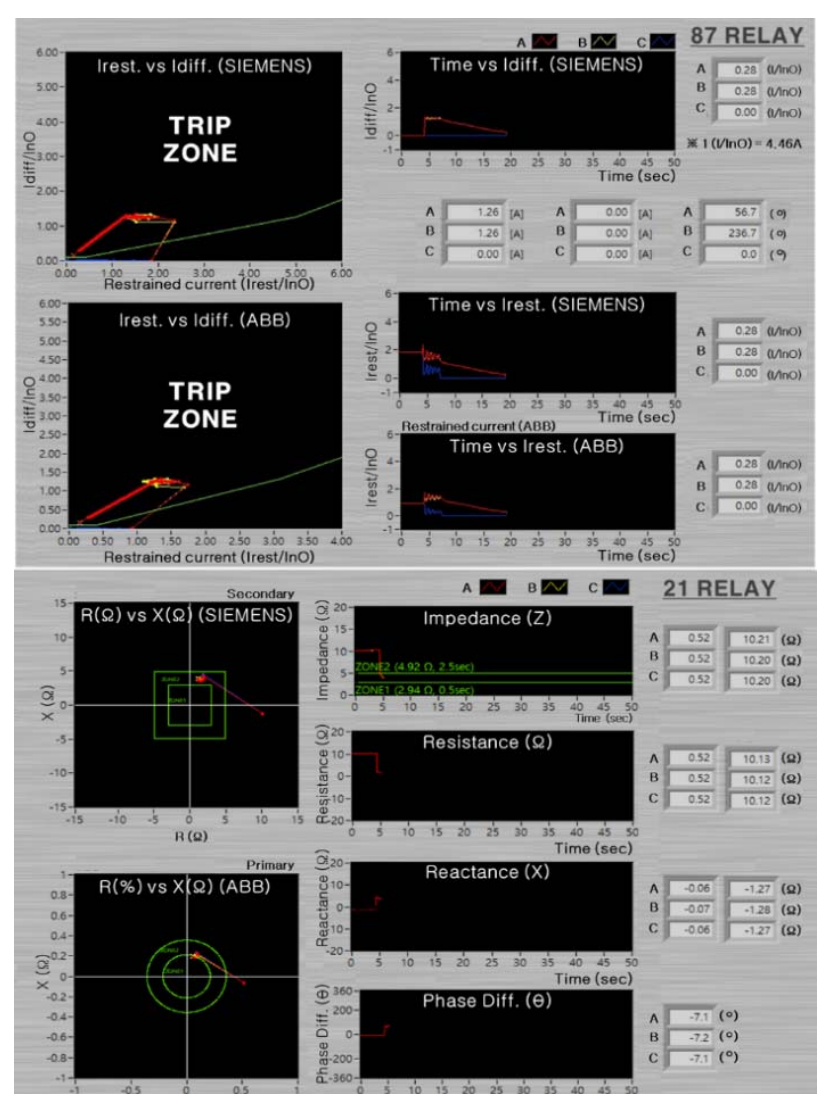

Fig. 10 HIL-test configuration of IED simulator.

The differential current relay (\#87) monitors the current ratio of the primary and secondary sides of the Scott transformer to check for abnormalities. And the distance relay (\#21) measures and monitors the impedance of the feeding section to check whether it is fault or not.

\subsection{Fault Simulation of Electric Railway SS}

Fig. 11 is a simulation result of accident currents that may occur in AC railway SS, and these results are compared with numerical values. It shows the simulation results using PSCAD/EMTDC, targeting $154 \mathrm{kV}$ single line-to-ground current, 3-phase short circuit current, $55 \mathrm{kV}$ line-to-line short circuit current, and $27.5 \mathrm{kV}$ single line-to-ground current. 

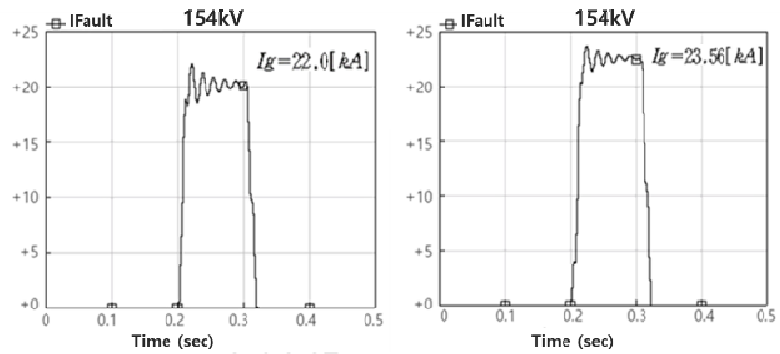

(a) Single line-to-ground

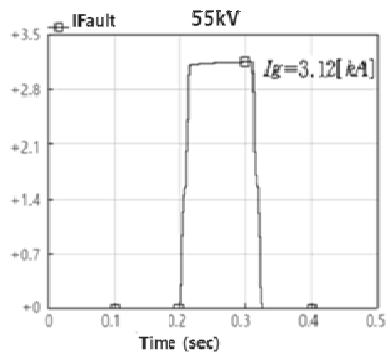

(b) 3-phase short circuit

(c) Line-to-line short circuit

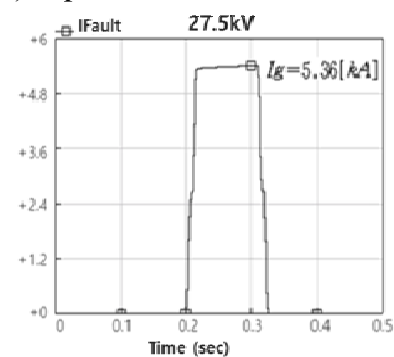

(d) Single line-to-ground

Fig. 11 AC railway fault current simulation result.

Table 6 compares the calculated and simulated values of the symmetric coordinate method. The 154 $\mathrm{kV}$ single line-to-ground current showed 92.4\% consistency, the $154 \mathrm{kV} \mathrm{3-phase} \mathrm{short} \mathrm{circuit} \mathrm{current}$ was $97.8 \%$, the $55 \mathrm{kV}$ line-to-line short circuit current was $92.9 \%$, and the $27.5 \mathrm{kV}$ single line-to-ground current was $97.0 \%$.

Table 6 Fault simulation current.

\begin{tabular}{lllll}
\hline Unit: kA & $154 \mathrm{kV}$ & $154 \mathrm{kV}$ & $55 \mathrm{kV}$ & $27.5 \mathrm{kV}$ \\
\cline { 2 - 5 } $\begin{array}{l}\text { Reference : } \\
\text { 100 MVA) }\end{array}$ & $\begin{array}{l}\text { Single line } \\
\text {-to-ground }\end{array}$ & $\begin{array}{l}\text { 3-phase } \\
\text { Short } \\
\text { circuit }\end{array}$ & $\begin{array}{l}\text { Internal } \\
\text { Short } \\
\text { circuit }\end{array}$ & $\begin{array}{l}\text { Single line } \\
\text {-to-ground }\end{array}$ \\
\hline (A)Calculation & 20.33 & 23.04 & 2.60 & 5.201 \\
(B)Simulation & 22.00 & 23.56 & 2.80 & 5.36 \\
(A)/(B) & $92.4 \%$ & $97.8 \%$ & $92.9 \%$ & $97.0 \%$ \\
\hline
\end{tabular}

The following Fig. 12 shows the ground fault current of the $27.5 \mathrm{kV}$ catenary line at the substation of the 'Nonsan $\sim$ Bongmyeong' section of the KTX Honam Line in Korea. The fault current value confirmed that the ground fault current was $5.57 \mathrm{kA}$ through the COMTRADE file stored in the relay, and showed $96.2 \%$ agreement with the $5.36 \mathrm{kA}$ obtained in the simulation.

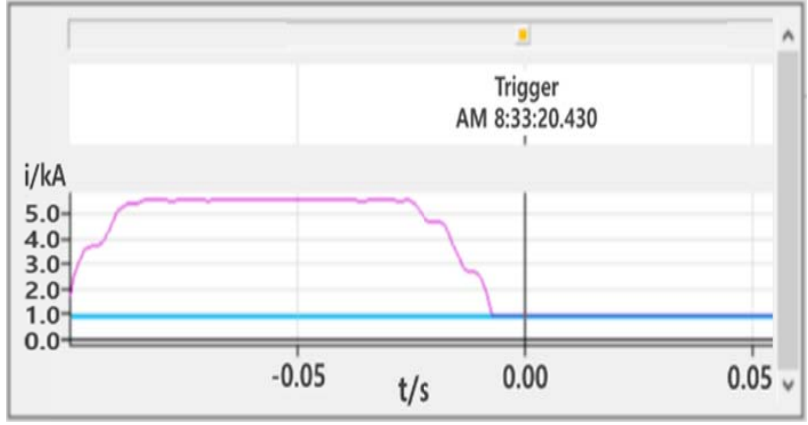

Fig. 12 Ground fault current of $27.5 \mathrm{kV}$ catenary line.

\section{Conclusion}

In a situation where the scale of the power system increases and becomes more complex, it is necessary to quickly and accurately respond to incidents through continuous data accumulation. In this study, hardware and software development required to build a performance evaluation system for digital protection relays was conducted, and simulations were conducted for each type along with reduced modeling using PSCAD/EMTDC for analysis of various accidents occurring in the AC railway power supply system. As a result, the $154 \mathrm{kV}$ single line-to-ground current showed $92.4 \%$ consistency, the $154 \mathrm{kV}$ 3-phase short circuit current showed $97.8 \%$, the $55 \mathrm{kV}$ line-to-line short circuit current was $92.9 \%$, and the $27.5 \mathrm{kV}$ single line-to-ground current showed $97.0 \%$ consistency. In the comparison of numerical calculations and simulations for ground fault and short circuit accidents, they tend not to be $100 \%$ identical, but almost identical. In addition, it showed 96.2\% agreement with the actual measurement result of the ground fault of the $27.5 \mathrm{kV}$ catenary line of the SS. In the future, the results of this research and development are expected to be used for various failure situation analysis and field training.

\section{Acknowledgments}

This study was conducted by the Ministry of Land, Infrastructure and Transport's Research Project on Railway Technology-Project (20RTRP-B146034-03). 


\section{References}

[1] Transport Analysis. 2014. "Railway in Sweden and Japan-A Comparative Study." In Swedish Transport Analysis, pp. 25-30.

[2] Han, Z. 2014. "Protection Coordination in Networks with Renewable Energy Sources.” M.Sc. thesis, University of Manchester.

[3] Kim, H. D., Cho, G. J., Huh, S. H., and Kim, C. H. 2016. "Study on the Overcurrent Relay Modeling and Protective Coordination for Overload in Domestic AC Electrical Railway System.” KIEE 65 (7): 1318-23.

[4] Kim, H. D. 2017. "A Study on the Protective Coordination and Setting of Overcurrent Relay in AC Railway Feeding System.” M.Sc. thesis, Sungkyunkwan University.
[5] Lee, J. H., Lee, J., Yoon, Y. B., and Cha, S. T. 2001. "Implementation and Verification of Distance Relaying Algorithm Using RTDS.” KIEE: 127-9.

[6] Henville, C., Hiebert, A., Folkers, R., and Wierckx, R. 2004. "Dynamic Simulations Challenge Protection Performance." In Proceedings of the 58th Annual Georgia Tech protection relaying Conference.

[7] Cho, Y. S., Park, S. W., Lee, C. K., Lee, U. H., and Kim, T. K. 2007. "An Implementation of Generator Protection Relay for Real Time Digital Simulator." Trans. KIEE 56 (2): 240-7.

[8] Kim, K. S. 2018. "Development of Real-Time Hybrid Simulation Platform for Analysis of Power System Electromagnetic Transients Using Real-Time Digital Simulator.” Ph.D. thesis, Korea University. 